\title{
Decentralized Treatment of Grey Water by Natural Coagulants in the Presence of Coagulation Aid
}

\author{
Roopika Nautiyal, Shivangi Uliana, Ishant Raj, Brij Shah, Kavish Rathore, Anantha Singh \\ Department of Civil Engineering, Pandit Deendayal Petroleum University \\ Gandhinagar District, Raisan, Gujarat, India \\ roopika.ncv14@sot.pdpu.ac.in; shivangi.ucv14@sot.pdpu.ac.in; ishant.rcv14@sot.pdpu.ac.in; \\ brij.scv14@sot.pdpu.ac.in; cps.kcv14@sot.pdpu.ac.in; anantha.singh@sot.pdpu.ac.in
}

\begin{abstract}
The treatment and re-use of grey water is becoming increasingly relevant in order to augment available potable water in most developed countries and countries with increasing population. Grey water is the wastewater captured from hand basins, showers, baths, laundry tubs and kitchen sinks, excluding those from toilets or urinals. The study focused on the treatability of grey water using natural coagulants and synthetic coagulation aid. The grey water sample collected from the hostel was used for the study. The initial characteristics of the grey water were assessed using pH, TDS, Turbidity, COD and BOD and measured as 9.41, 1240 mg/l, 165 NTU, $3618 \mathrm{mg} / \mathrm{l}$ and $1543 \mathrm{mg} / \mathrm{l}$ respectively. The natural coagulant used for the study was freely available Sapodilla seeds, and the coagulation aid used was Alum. The coagulation with Sapodilla seeds proved to remove about 50\% of turbidity, 30\% COD for a seed concentration of $50 \mathrm{mg} / \mathrm{L}$. The coagulation with coagulation aid alum removed $20 \%$ COD and $40 \%$ of turbidity. Addition of coagulation aid to the coagulant proved to remove $90 \%$ of turbidity and $70 \%$ COD for alum concentration of $10 \mathrm{mg} / \mathrm{l}$. The present study focuses on the development of a decentralized grey water treatment unit comprised of natural coagulants to ensure the reuse standard.
\end{abstract}

Keywords: Grey water, natural coagulants, reuse standard, Sapodilla seeds

\section{Introduction}

In many developing countries, access to clean and safe water is a major problem. According to the UN, 1.1 billion people still do not have access to an adequate supply of drinking water and these people are among the world's poorest. Poor water quality is a key cause of poor livelihood and poor health with $80 \%$ of all diseases in developing countries being water related. The global increase in water demand, water shortage due to low rainfall, economic and environmental issues, leads the researchers to show interest in wastewater recycling [1].

As we know that the Surface water either from rivers or rain fed ponds is the main source of water supply. This water is vulnerable to various forms of pollution generated from different sources mainly households, agriculture and industries. The removal of organic and inorganic material from raw water is essential before it can be disinfected for human consumption. Rainwater, grey water and desalinated sea water are considered to be good alternative resources. Rain water harvesting is one of the most useful options of water conservation but it has some limitations such as it is only useful for areas receiving good amount of rainfall throughout the year. On the other hand, seawater desalination results in increased emission of $\mathrm{CO} 2$ and other pollutants to the atmosphere and causes disturbance to the adjacent marine environment [2].

Hence, grey water reuse is a viable option that can be very useful in water arid and semi-arid areas. Grey water recycling is now accepted as a sustainable solution to the general increase of the fresh water demand, water shortages and for environment protection. The most common application for grey water reuse is toilet flushing which can reduce water demand within dwellings by up to $30 \%$. However, other applications such as irrigation of parks, school yards, cemeteries and golf courses, vehicle washing, fire protection and air conditioning are practiced [3]. The issue of grey water recycling raised attention in the past decades, primarily as a possible solution for water shortages in developing countries, and it is performing a rapid growth on global level today [4].

Grey water is all wastewater generated in households, private, public or commercial properties without any input from toilets, bidets, urinals or without fecal contamination [5]. Sources of grey water include sinks, showers, baths, washing 
machines or dish washers [6]. Grey water contains many of the same contaminants as sewage water, and are generally present in lower concentrations than present in sewage water, hence they are well in range of the international bathing and irrigation water standards.

Grey water constitutes about $80-85 \%$ of total household sewage produced and has lower concentration of organic matter $(0.01 \%)$ and fewer pathogens as compared to septic wastewater which constitutes $15-20 \%$ of total sewage produced and has high concentration of organic matter (1\%). Many people have investigated the various wastewater treatment methods extensively on the international and national levels [7]. The grey water reuse has great potential in wide range of applications in domestic, commercial, institutional as well as industrial buildings. Inorganic coagulants are particularly effective on raw water with low turbidity (TSS concentration). Some of the inorganic coagulants are Alum (Aluminum Sulfate), Ferric Chloride, Polyaluminum Chloride $(\mathrm{PACl})$ \& Aluminum Chloro hydrate $(\mathrm{ACH})$. These coagulants are not always available at a reasonable price, can leave undesirable large volumes of non-biodegradable sludge and also have serious effects on human body. As a consequence of the above mentioned drawbacks, there was a need to develop alternative, cost effective and environmentally friendly coagulants.

A number of effective coagulants from plant origin have been identified: Nirmali [8], Okra, red bean, sugar and red maize [9], M. oleifera [10], ManilkaraZapota and a natural coagulant from animal origin; chitosan. The higher coagulant efficiency of natural coagulants allows more active colloidal aggregation and more consistent floc than with synthetic reagents, so that the necessary quantity of product is reduced and also the associated costs.

The Cheeku is an indigenous, naturally derived coagulant, namely seed material from the multipurpose tree ManilkaraZapota (commonly referred as Cheeku or Sapodilla) in the treatment of Grey water for Domestic Reuse. The seed kernel oil of Sapodilla is used as a skin ointment. The residue of this seed, after the extraction of oil, can be applied as a poultice on painful skin afflictions. The crushed seeds of this fruit act as a diuretic, thus helping to expel bladder and kidney stones. It provides protection against kidney diseases as well. The ground seeds can be applied as a paste for alleviating stings and insect bites. Oil extracted from its seeds helps in moisturizing and softening your hair, thus making it more manageable. It imparts sheen and is considered excellent for curly hair. It gets absorbed easily without leaving a greasy residue [11].

The seed kernels contain significant quantities of a series of low molecular weight, water-soluble proteins like phenolic compounds (D-quercitol, methyl chlorogenate, dihydromyricetin, quercitrin and saccharose ) which, in solution, carry an overall positive charge. The main objective of the study was to investigate the effect of natural coagulations (selected seeds) for the treatment of grey water. The effect of inorganic coagulant aid along with the natural coagulant on the treatment of grey water was also studied.

\section{Materials and Methods}

Preparation of Fine Seed Powder:

Sapodilla seeds were obtained from different areas of Ahmedabad. High quality seeds, those which are new and not infected with diseases; were selected. The seeds were de-shelled (manually) and then were dried in sunlight for 10 hours. The kernel so obtained was crushed and then grinded to a fine powder by means of a domestic food blender. This Fine Powder so obtained is then kept in closed container.

Preparation of the Extract:

The $2 \mathrm{~g}$ of fine powdered seed was mixed well with $100 \mathrm{ml}$ distilled water to extract the coagulant present in the seeds. The suspension obtained was then stirred using a magnetic stirrer for 10 minutes for homogeneous mixing and then filtered. The extract was then stored in the refrigerator to avoid degradation.

Experimental Process:

The grey water was collected from hostel and the characteristics of the grey water is given in Table 1 . The coagulation process was done by Jar Test Experiment. $500 \mathrm{ml}$ of grey water was taken in a beaker having the capacity of 1L. Different concentrations of Sapodilla were used varying from $1 \mathrm{mg} / 1$ to $200 \mathrm{mg} / \mathrm{l}$. Rapid mixing was carried out first at $120 \mathrm{rpm}$ speed for 2 minutes and then slow mixing at $20 \mathrm{rpm}$ speed for 10 minutes follow-up by sedimentation for $20 \mathrm{~min}$. The outlet was analyzed for $\mathrm{pH}$, turbidity, COD and TDS as per IS: 3025 . To investigate the effect of coagulant aid $10 \mathrm{mg} / \mathrm{l}$ alum was added in all the test tubes along with natural coagulant. 
Table 1: Characteristics of Grey Water used for the study.

\begin{tabular}{|l|c|}
\hline \multicolumn{1}{|c|}{ PARAMETER } & $\begin{array}{c}\text { INITIAL } \\
\text { INVESTIGATION }\end{array}$ \\
\hline $\mathrm{pH}$ & 9.41 \\
\hline $\mathrm{COD}(\mathrm{mg} / \mathrm{l})$ & 3618 \\
\hline $\mathrm{BOD}(\mathrm{mg} / \mathrm{l})$ & 1543 \\
\hline TDS $(\mathrm{mg} / \mathrm{l})$ & 1240 \\
\hline Turbidity $(\mathrm{NTU})$ & 165 \\
\hline
\end{tabular}

\section{Results and Discussion}

Common Contaminants found in grey water are salts, food particles, oil, surfactants and microorganisms. Indeed, the grey water characteristics are highly variable as influenced by factors such as lifestyle, social and cultural behaviour of residents, and water availability [12]. To study the effect of Sapodilla seeds concentration on the removal of turbidity and $\mathrm{COD}$, the concentration was varied from $2.5 \mathrm{mg} / \mathrm{L}$ to $200 \mathrm{mg} / \mathrm{L}$. The seeds of Sapodilla proved to be useful for the removal of solids from grey water. The turbidity reduced by $65 \%$, COD reduced by $35-45 \%$ and TDS removal is $30 \%$. The amount of removal obtained was more than the average value given by Vakilet. al. in 2014 [13]. By increasing the concentration of the coagulant, greater removal efficiency is expected. The increase in seed concentration increases the removal efficiency to a certain limit and with further increase in coagulant dosage decreased the removal efficiency considerably. When the dosage was increased from $1 \mathrm{mg} / \mathrm{L}$ to $5 \mathrm{mg} / \mathrm{L}$, the turbidity removal increased from $27 \%$ to $64 \%$. With further increase from $5 \mathrm{mg} / \mathrm{L}$ to $50 \mathrm{mg} / \mathrm{L}$ dosage decreased the turbidity removal considerably ie. from $64 \%$ to $41 \%$. This phenomenon states that the ionic concentration of the extract is very high and increasing the dosage concentration increases the ions of same charge.

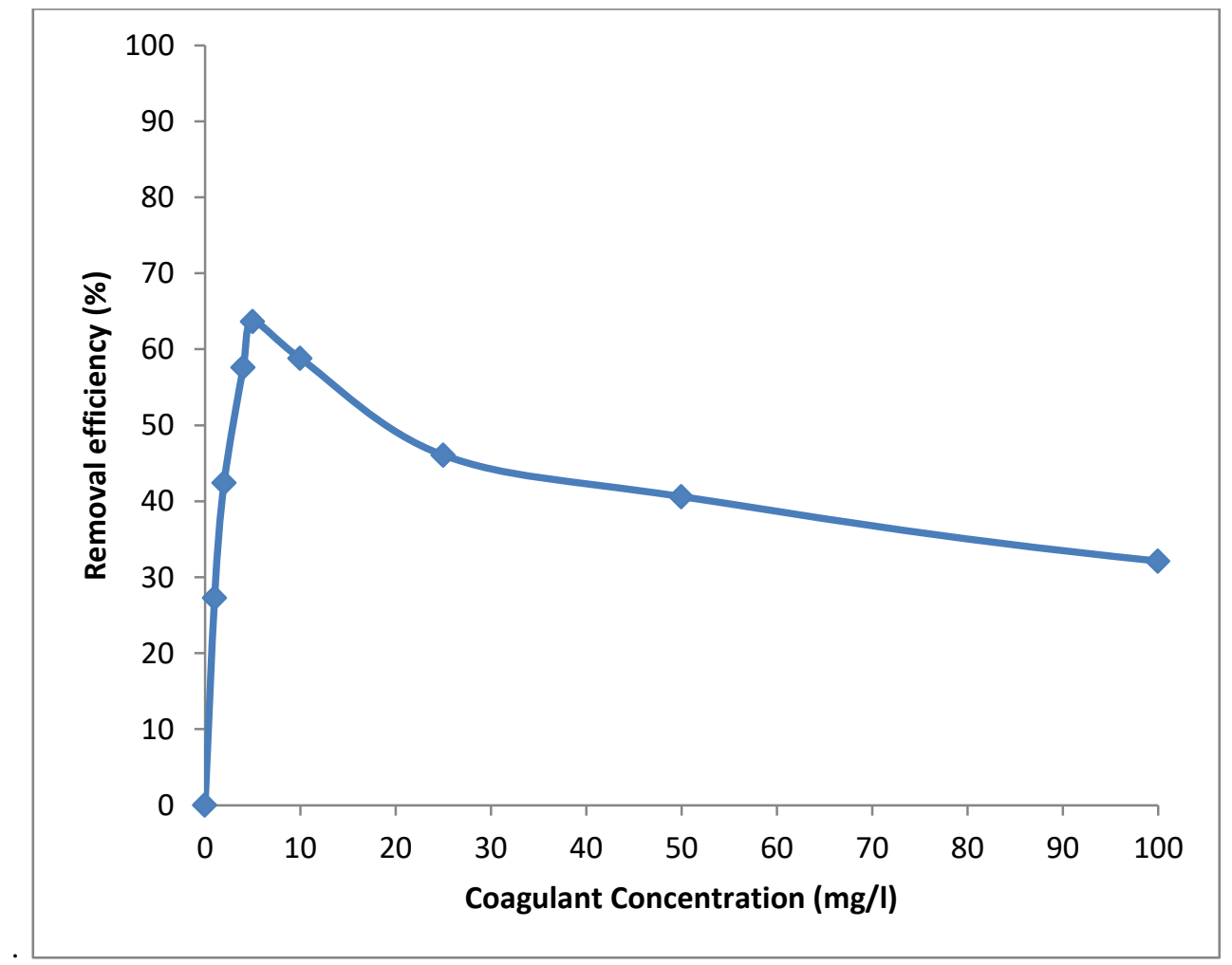

Fig. 1: Turbidity removal with different concentrations of Sapodilla seed Coagulant.

Study by Saenz et al., 2004 [11] have established that mucilage in cactus contains carbohydrates such as 1-arabinose, d-galactose, 1-rhamnose, d-xylose, and galacturonic acid which accounts for it's high removal efficiency. The Sapodilla 
seed kernels contain significant quantities of a series of low molecular weight, water-soluble proteins like phenolic compounds (D-quercitol, methyl chlorogenate, dihydromyricetin, quercitrin and saccharose ) which, in solution, carry an overall positive charge. The proteins are considered to act similarly to synthetic, positively charged polymer coagulants. When added to raw water the proteins bind to the predominantly negatively charged particulates that make raw waters turbid (silt, clay, bacteria etc.). Under proper agitation these bound particulates then grow in size to form the flocs, which may be left to settle by gravity or be removed by filtration. Sapodilla seeds can be used as coagulating agent as they contain proteins and carbohydrates that have proved to be effective in the treatment of Grey Water. Coagulation aid can be used in the trial process of removing solids from grey water.

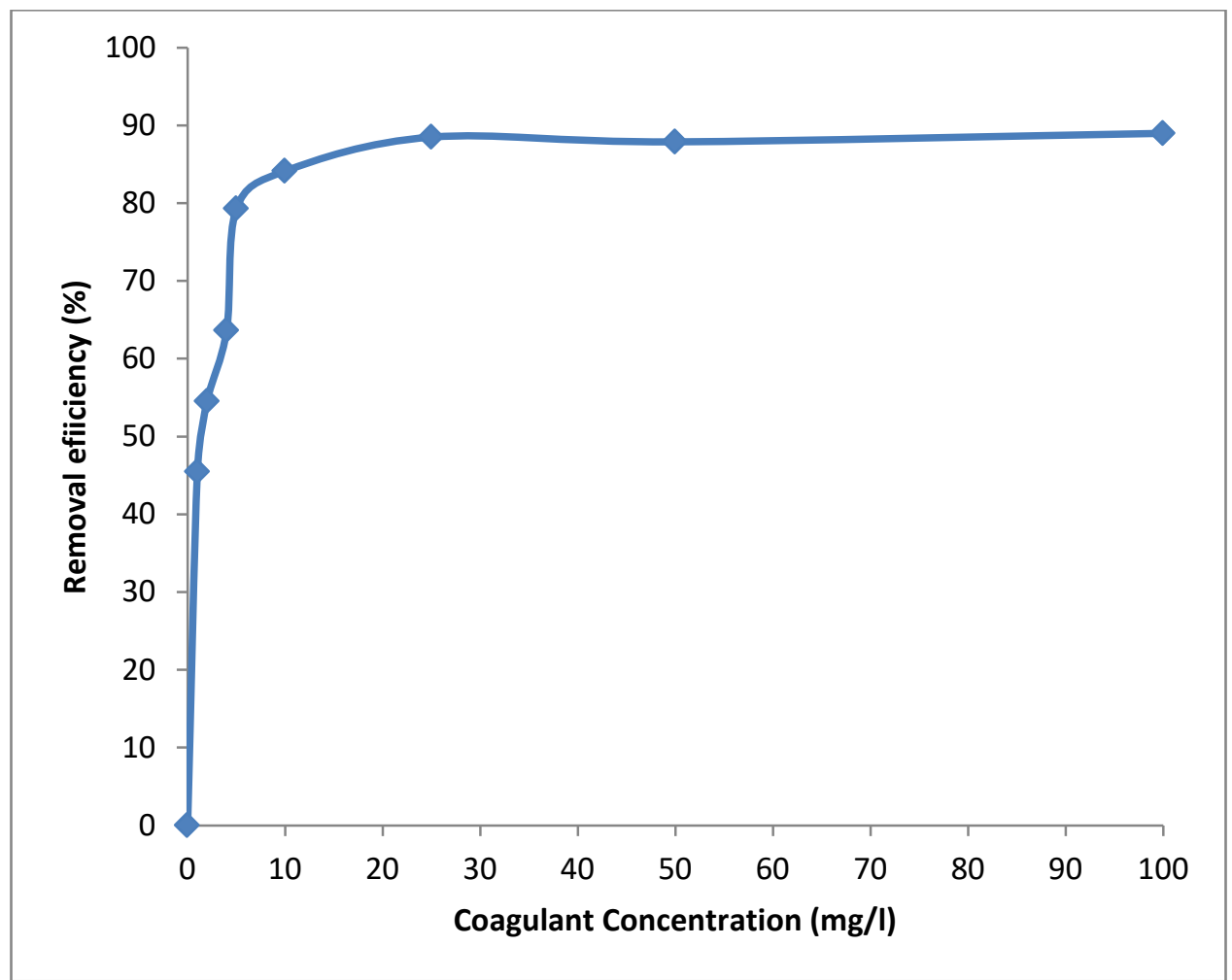

Fig. 2: Turbidity removal with different concentrations of Sapodilla seed Coagulant in the presence of Coagulant aid (10 mg/L).

To improve the removal efficiency of the coagulation process with natural coagulant, the coagulant aid is used. In the present process alum was used as the coagulant aid to study the effect of positive charged ion as the catalyst in the coagulation process with natural coagulant. $10 \mathrm{mg} / \mathrm{L}$ of alum was added along with the above stated natural coagulant dosage and effect on turbidity and COD removal was investigated. It was observed that the coagulant aid enhances the removal efficiency considerably with the increase in the natural coagulant dosage. Around $88 \%$ of the removal efficiency was obtained when the coagulant dosage was increased to $25 \mathrm{mg} / \mathrm{L}$. It was also noted that the efficiency decline due to the increase in the natural coagulant was not observed in the presence of coagulant aid. The removal efficiency remains almost same with the further increase in the natural coagulant dosage also. The COD removal was also observed to be increasing with respect to the increase in coagulant dosage.

\section{Conclusion}

Sapodilla seeds proved to be effective in the removal of an appreciable amount of turbidity and COD from the grey water. The sapodilla seed coagulant removes $65 \%$ of turbidity from the grey water and $45 \%$ of COD present in the grey water. The addition of alum as the coagulant aid increases the removal efficiency of natural coagulant. With the help of coagulation aid and concentration variation of the coagulants, greater removal efficiency was obtained. The studies proved that around $90 \%$ of the turbidity and $65 \%$ of the COD can be removed from the grey water by using natural coagulants in 
combination with coagulant aid. The natural coagulation of grey water can be an alternative technology for the decentralised treatment of grey water.

\section{Acknowledgements}

We would like to thank our college for funding our project through ORSP department of our college. We would also like to thank department of Civil engineering for providing us best environmental lab along with Dr. Debasis Sarkar and Dr. H.B. Raghavendra for their support.

\section{References}

[1] E. Eriksson, K. Auffarth, M. Henze A. Ledin, "Characteristics of grey wastewater," Urban Water, vol. 4, no. 1, pp. 85-104, 2002.

[2] M. M. Karpiscak, K. E. Foster, N. Schmidt, "Residential water conservation," Water Res., vol. 26, pp. 939-948, 1990.

[3] W. Lu, A.Y.T. Leung, "A preliminary study on potential of developing shower/laundry wastewater reclamation and reuse system," Chemosphere, vol. 52, pp. 1451-1459, 2003.

[4] O.R. Al-Jayyousi, "Greywater reuse: towards sustainable water management," Desalination, 156, pp. 181-192, 2003.

[5] E. Eriksson, K. Auffarth, A.-M. Eilersen, M. Henze, A. Ledin, "Household chemicals and personal care products as sources for xenobiotic organic compounds in grey wastewater," Water SA, vol. 29, no. 2, pp. 135-146, 2003.

[6] V. L. Mohan, M. M. Ahammed, T.N. Abhilash, "Greywater Treatment Using Electrocoagulation," $12^{\text {th }} I W A$ Specialist Conference on Small Water and Wastewater systems, Oman, 2014.

[7] L. Bhausaheb, P. Saroj, M. Sane, "Design and Economical Performance of Greywater Treatment Plant in Rural Region," International Journal of Civil and Environmental Engineering, vol. 2, no. 1, 2010.

[8] P. N. Tripathi, M. Chaudhuri, S. D. Bokil, "Nirmali Seed A Naturally Occurring Coagulant," Indian Journal of Environmental Health, vol. 18, no. 4, 1976.

[9] K. R. Gunaratna, B. Garcia, S. Andersson and G. Dalhammar, "Screening and evaluation of natural coagulants for water treatment," Water Science and Technology - Water Supply, vol. 7, no. 5/6, pp. 19, 2007.

[10] S. A. A. Jahn, "Using Moringa Seeds as Coagulants in Developing Countries," Journal American Water Works Association, vol. 80, no. 6, pp. 43-50, 1988.

[11] C. Saenz, E. Sepulveda, B. Matsuhiro, "Opuntiaspp mucilage's: a functional component with industrial perspectives," J Arid Environ, vol. 57, pp. 275-290, 2004.

[12] E. A. Couto, M. L. Calijuri, P. P. Assemany, A. F. Santiago, L. S. Lopes, "Greywater treatment in airports using anaerobic filter followed by UV disinfection: an efficient and low cost alternative," Journal of Cleaner Production, vol. 106, pp. 372-379, 2015.

[13] K. A. Vakil, M. K. Sharma, A. Bhatia, A. A. Kazmi, S. Sarkar, "Characterization of Greywater in an Indian middleclass household and investigation of physicochemical treatment using Electrocoagulation," Separation and Purification technology, vol. 130, pp. 160-166, 2014. 